\title{
The association between periodontal disease and metabolic syndrome among outpatients with diabetes in Jordan
}

\author{
Rola Alhabashneh ${ }^{1,2^{*}}$, Yousef Khader ${ }^{2}$, Zaid herra ${ }^{1}$ and Farah Asa'ad ${ }^{1}$
}

\begin{abstract}
Background: To date, conflicting results have been reported about the association between metabolic syndrome (MetS) and periodonttitis.

Methods: Two hundred and eighty patients with type 2 diabetes were recruited from outpatients visiting diabetes clinics in Islamic Hospital, Amman-Jordan. The oral hygiene and the periodontal status of all teeth, excluding third molars, were assessed using the plaque index of Silness and Löe, the gingival index of Löe and Silness, probing pocket depth (PPD), and clinical attachment level (CAL). Data were analyzed using the general linear model multivariate procedure with average PPD, average CAL, percent of teeth with CAL $\geq 3 \mathrm{~mm}$, and percent of teeth with PPD $\geq 3 \mathrm{~mm}$ as outcome variables and diabetes, MetS and its individual components as predictors.
\end{abstract}

Results: Overall, $83.2 \%$ of patients with diabetes had MetS. In the multivariate analysis, patients with MetS had a significantly more severe periodontitis, as measured by average PPD and average CAL $(P<0.005)$. The extent of periodontitis, as measured by the percent of teeth with CAL $\geq 3 \mathrm{~mm}$ and the percent of teeth with PPD $\geq 3 \mathrm{~mm}$, was also significantly greater among patients with MetS $(P<0.005)$. As the number of metabolic components additional to diabetes increased, the odds of having periodontitis increased, and the odds were greatest when all the components additional to diabetes were present ( $\mathrm{OR}=10.77,95 \% \mathrm{Cl}: 2.23$-51.95).

Conclusion: Patients with MetS displayed more severe and extensive periodontitis. Having other MetS components additional to diabetes increased the odds of having periodontitis.

Keywords: Periodontitis, Diabetes, Metabolic syndrome

\section{Introduction}

Metabolic syndrome (MetS) is a complex collection of components that are thought to arise from a visceral fattype obesity involving hypertension and abnormal glucose and lipid metabolism [1]. The prevalence of MetS increases with age and varies with ethnicity and race [2]. The prevalence of MetS among adults in USA is $22.9 \%$ [3], which is comparable to its prevalence among Canadian adult population (19.1\%) [4]. Higher MetS prevalence rates have been observed in the Eastern Mediterranean countries and Arab populations [5-9]. In Jordan, the

\footnotetext{
* Correspondence: rolaperio@yahoo.com

'Preventive Department-Periodontics, College of Dentistry, Jordan University of Science and Technology, PO Box: 3030, Irbid 22110, Jordan

${ }^{2}$ Department of Community Medicine, Jordan University of Science and Technology, PO Box: 3030, Irbid 22110, Jordan
}

prevalence of MetS among adults was alarmingly high (36.6 \%) [10]. Lower prevalence of MetS has been found among European adults [11].

Periodontal disease is a group of infectious diseases triggered by periodontopathogens [12]. It is considered the most common chronic infection worldwide and in the US $[13,14]$. Periodontitis and MetS are multi-factorial diseases sharing a common inflammatory pathway. Many people with MetS have a low grade systemic inflammation which is reported by elevated levels of inflammatory mediators such as C-reactive protein (CRP), interleukin-6 (IL6 ), and tumor necrotic factor- $\alpha$ (TNF- $\alpha$ ). Moreover, people who have periodontitis, which is a chronic inflammation, also have elevated levels of inflammatory markers (CRP, IL-6 and TNF- $\alpha$ ) $[15,16]$. There is growing evidence suggesting an association between periodontal disease and 
MetS components since positive correlation between obesity, hypertension, hyperglycemia and hyperlipidemia with periodontal disease has been reported [17, 18]. MetS has been shown to be associated with the prevalence, extent and severity of periodontal disease $[15,19-21]$ and a recent systematic review concluded that subjects affected by MetS are nearly twice more likely to have periodontitis than the rest of the population [22]. Furthermore, periodontal disease has effects on the glycemic control [23] and lipid metabolism [24].

This study is built on the concept that the three diseases (MetS, periodontal disease and diabetes mellitus) share common pathogenesis. The aim of this study was to assess the association between MetS and periodontal disease among patients with type 2 diabetes in Jordan.

\section{Methods}

\section{Study population and sampling}

The study was approved by the University Ethical Committee at Jordan University of Science and Technology. The participants were recruited from outpatients visiting the diabetes clinics in Islamic Hospital Amman-Jordan, over a period of six months between June-November 2011. All participants were interviewed and examined after they signed a written consent form. Patients were selected using systematic random sampling technique by choosing every third patient (i.e. patients registered with numbers such as $3,6,9,12 \ldots)$ attending the clinics. About half of the interviewed patients met the inclusion criteria. Patients with a history of a systemic condition or medication use that might influence the severity of periodontitis were excluded (i.e. patients with a history of thyroid diseases, chronic renal problems and connective tissue diseases). Pregnant women and patients who were edentulous and those who had undergone periodontal treatment within the preceding 6 months were also excluded.

The power of this study to detect the association between MetS and periodontal disease given our sample size was calculated. To detect a minimal odds ratio of 3 at alpha level of $5 \%$ in a sample that included 233 patients with MetS and assuming that $14 \%$ of patients without MetS had periodontal disease, the power was calculated as $99 \%$. The power calculations were performed using Sample size online calculator (http://sampsize. sourceforge.net/iface/s3.html).

\section{Data collection}

Data were collected by a questionnaire answered by patients through personal interview and clinical examination. The questionnaire included questions about socio-demographic variables, medical history, smoking history, previous dental history, oral hygiene practice and clinical findings associated with periodontal examination.
Participants were assured of the confidentiality of all obtained information and that collected data will only be used for scientific purposes.

\section{Diabetes mellitus}

Only patients with type 2 diabetes were included in this study. Patients were diagnosed with diabetes mellitus if they had fasting plasma glucose (FPG) $\geq 100 \mathrm{mg} / \mathrm{dl}$ or if they were taking medications for type 2 diabetes mellitus. Control of diabetes mellitus was investigated through glycated hemoglobin test (HbA1c). The FPG and HbA1c values were taken from recent tests included in patients' files.

\section{Hypertension}

Hypertension was defined as systolic blood pressure $\geq$ $130 \mathrm{mmHg}$ or diastolic blood pressure $\geq 85 \mathrm{mmHg}$, or under treatment of previously diagnosed hypertension as reported in patients' medical records. Blood pressure was measured by a qualified nurse using a mercury sphygmomanometer on the same day of periodontal examination.

\section{Hyperlipidemia}

The diagnosis of hyperlipidemia was made by an endocrinologist based on the measurements of triglycerides (TG) and high density lipoproteins (HDL): TG $\geq 150 \mathrm{mg} /$ $\mathrm{dl}$ and/or (HDL cholesterol level $<40 \mathrm{mg} / \mathrm{dl}$ in males and $<50 \mathrm{mg} / \mathrm{dl}$ in females), or if the patient was currently on specific treatment for lipid abnormalities.

\section{Obesity}

The participants were diagnosed as obese by measuring the waist circumference (WC), using a circumference measuring tape. The readings were rounded to the nearest centimeter. The diagnosis was made if the waist circumference was $\geq 94 \mathrm{~cm}$ for men and $\geq 80 \mathrm{~cm}$ for women. The weight was measured using a mechanical flat scale to the nearest kilogram, and height was measured to the nearest centimeter using a measuring rod. All these measurement were taken at the same day of examination, with the participants wearing light clothing and no shoes.

\section{MetS definition}

MetS was defined according to the International Diabetes Federation (IDF) definition [25]. According to the IDF definition, a person was defined as having $\mathrm{MeS}$ if he or she had central obesity (defined as waist circumference $\geq 94 \mathrm{~cm}$ for men and $\geq 80 \mathrm{~cm}$ for women, with ethnicity specific values for other groups) plus any two of the following four factors: 1) Raised TG level: $\geq 150 \mathrm{mg} / \mathrm{dL}$ (1.7 mmol/L), or specific treatment for this lipid abnormality, 2) Reduced HDL cholesterol: $<40 \mathrm{mg} / \mathrm{dL}(1.03 \mathrm{mmol} / \mathrm{L})$ in males and $<50 \mathrm{mg} / \mathrm{dL}(1.29 \mathrm{mmol} / \mathrm{L})$ in females, or specific treatment for this lipid abnormality, 3) Raised blood pressure: systolic 
$\mathrm{BP} \geq 130$ or diastolic $\mathrm{BP} \geq 85 \mathrm{~mm} \mathrm{Hg}$, or treatment of previously diagnosed hypertension, 4) Raised fasting plasma glucose (FPG) $\geq 100 \mathrm{mg} / \mathrm{dL}(5.6 \mathrm{mmol} / \mathrm{L})$, or previously diagnosed type 2 diabetes.

\section{Periodontal clinical examination}

The oral hygiene and the periodontal status of all teeth, excluding third molars, were assessed using, plaque index (PI) of Silness \& Löe (1964) [26], probing pocket depth (PPD), and clinical attachment loss (CAL). Sterile dental mirrors and explorers were used to assess plaque accumulation and gingival status. $\mathrm{Hu}$-Friedy periodontal probes with Williams's markings (Diatech, Switzerland) were used to measure PPD and CAL. All teeth (excluding third molars), and six surfaces of each studied tooth (mesio-facial, mid-facial, disto-facial, mesio-lingual, midlingual, and disto-lingual) were assessed and scored for PI, GI, PPD and CAL. Plaque index was scored as follows: $0=$ no plaque/debris $1=\mathrm{A}$ film of plaque adhering to the free gingival margin and adjacent area of the tooth. 2 = Moderate accumulation of soft deposit $\mathrm{s}$ within the gingival pocket, or the tooth and gingival margin which can be seen with the naked eye. 3 = Abundance of soft matter within the gingival pocket and/or on the tooth and gingival margin. The highest score of each reading was taken into consideration. Data were recorded on periodontal examination form.

Disease extent was defined by the percentage of deep pockets. The mean of the deepest reading for PPD and CAL was calculated within each mouth by dividing the value of deepest pockets on the total number of deep pockets. Periodontitis was defined as presence of four or more teeth with highest reading of $P P D \geq 3 \mathrm{~mm}$ and $\mathrm{CAL} \geq 3 \mathrm{~mm}$ [27].

\section{Reliability of questionnaire and periodontal examination} Clinical examinations were performed by one skilled examiner (RA). Before the beginning of the study, the measurement reliability was determined on the basis of examinations performed on 10 patients with severe periodontitis. Of the replications, $98 \%$ were within $1 \mathrm{~mm}$ for PDs, and $97 \%$ were within $1 \mathrm{~mm}$ for CALs.

\section{Data management and analysis}

The Statistical Package for Social Sciences software (SPSS Inc., version 15, Chicago, IL, USA) was used for data processing and data analysis. Characteristics of subjects' variables were described using frequency distribution for categorical variables and mean and standard deviation for continuous variables. The $\mathrm{Chi}^{2}$ test was used to assess the association between categorical variables.

The multivariate analysis of the association between different disease status and periodontal parameters (average $\mathrm{PPD}$, average CAL) and percentage of teeth with (PPD $\geq 3 \mathrm{~mm}, \mathrm{PPD} \geq 4 \mathrm{~mm}, \mathrm{PPD} \geq 5 \mathrm{~mm}, \mathrm{PPD} \geq 6 \mathrm{~mm}, \mathrm{CAL}$ $\geq 3 \mathrm{~mm}, \mathrm{CAL} \geq 4 \mathrm{~mm}, \mathrm{CAL} \geq 5 \mathrm{~mm}$ and $\mathrm{CAL} \geq 6 \mathrm{~mm}$ ) was conducted using the General Linear Model procedure. Multivariate binary logistic regression was conducted to determine the association between each disease group (i.e. group of patients with MetS and group of patients with diabetes) and the prevalence of periodontal disease after adjusting for important variables. All variables that were significantly associated with periodontal disease constituted the best regression model. The association between obesity, hypertension, and hyperlipidemia, with diabetes and periodontal disease was tested, in separate models, for each disease group after adding that indicator to the best model. The association between diabetes, the increasing number of MetS components and periodontal disease was tested too. The statistical significance of the two-way interactions between independent variables was assessed with the use of forward stepwise regression.

The two-way interaction terms, one at a time, were added in the model containing all the main effects and were assessed for their significance using the likelihood ratio test. Crude odds ratios (ORs) and their $95 \%$ confidence interval (CI) were calculated. A p-value of $<0.05$ was considered statistically significant.

\section{Results}

This study included a total of 280 patients with type 2 diabetes mellitus. Overall, $83.2 \%$ of patients with diabetes had MetS. The patients aged between 21 and 80 years with a mean $( \pm S D)$ age of $53.8( \pm 9.6)$ years. Sociodemographic, dental, anthropometric, clinical, and relevant characteristics of the participants are shown in Tables 1 and 2 . About half (50.7\%) of patients were males and $49.3 \%$ were females. About one third of patients (32\%) had university level education. Almost $30 \%$ of patients reported brushing their teeth twice daily. Nearly half $(51.8 \%)$ of patients had duration of diabetes of $\leq 5$ years, $28 \%$ were taking insulin therapy, and $93.2 \%$ were on oral hypoglycemic medications. Only $21.8 \%$ of patients were well controlled (HbA1c $\leq 6.5 \%)$. The majority $(87.5 \%)$ of the participants were obese, $87.1 \%$ had elevated blood pressure, $65 \%$ had increased triglycerides level ( $\geq 150 \mathrm{mg} / \mathrm{dl}$ ), and $46.1 \%$ had low HDL level.

Table 3 illustrates the extent and severity of periodontal disease according to MetS after adjusting for average PI, age, family income, residency area, smoking, teeth brushing and number of missing teeth. Patients with MetS had a significantly higher mean PPD $(P<0.005)$ and CAL $(P=0.001)$. The extent of periodontal disease was also significantly higher in patients with MetS as measured by average percent of teeth with the deepest CAL $\geq 3 \mathrm{~mm}(P<0.005), \mathrm{CAL} \geq 4 \mathrm{~mm}(P<0.005)$, and $\mathrm{CAL} \geq 5 \mathrm{~mm}(P<0.005)$. 
Table 1 Socio-demographic, dental and relevant characteristics of 280 patients with type 2 diabetes

\begin{tabular}{|c|c|}
\hline Variable & n (\%) \\
\hline \multicolumn{2}{|l|}{ Gender: } \\
\hline Male & $142(50.7)$ \\
\hline Female & $138(49.3)$ \\
\hline \multicolumn{2}{|l|}{ Age (years): } \\
\hline$\leq 45$ & $56(20.0)$ \\
\hline $46-55$ & $107(38.2)$ \\
\hline$>55$ & $117(41.8)$ \\
\hline \multicolumn{2}{|l|}{ Family income (JD): } \\
\hline$\leq 500 \mathrm{JD}$ & $168(60)$ \\
\hline$>500$ & $112(40)$ \\
\hline \multicolumn{2}{|l|}{ Education: } \\
\hline Elementary & $107(38.2)$ \\
\hline Secondary & $86(30.7)$ \\
\hline University & $87(31.1)$ \\
\hline \multicolumn{2}{|l|}{ Residency area: } \\
\hline Urban & $271(96.8)$ \\
\hline Rural & $9(3.2)$ \\
\hline \multicolumn{2}{|l|}{ Smoking: } \\
\hline Non-smoker & $185(66.1)$ \\
\hline X-smoker & $34(12.1)$ \\
\hline Smoker & $61(21.8)$ \\
\hline \multicolumn{2}{|l|}{ Teeth brushing: } \\
\hline Infrequent & $87(31.1)$ \\
\hline Once/day & 109 (38.9) \\
\hline Twice/day & $84(30.0)$ \\
\hline Having fixed prosthesis & $186(66.4)$ \\
\hline \multicolumn{2}{|l|}{ Number of missing teeth: } \\
\hline 0 & $53(18.7)$ \\
\hline $1-7$ & $120(43.0)$ \\
\hline $8-18$ & $107(40.3)$ \\
\hline Periodontitis & $111(39.6)$ \\
\hline
\end{tabular}

Table 4 demonstrates the extent and severity of periodontal disease according to the number of metabolic abnormalities in the multivariate analysis. As the number of metabolic abnormalities in addition to diabetes increased; the severity of periodontal disease, as measured by average PPD and average CAL, significantly increased. The increasing number of components of MetS was significantly associated with higher extent of periodontal disease as measured by the average percent of teeth with CAL $\geq 3 \mathrm{~mm}, \geq 4 \mathrm{~mm}, \geq 5 \mathrm{~mm}$, and $\geq 6 \mathrm{~mm}$.

The prevalence of periodontal disease according to MetS and its components is shown in Table 5. The prevalence of periodontal disease was higher among those who
Table 2 Anthropometric, clinical and relevant characteristics of 280 patients with type 2 diabetes

\begin{tabular}{lc}
\hline Variables & $\mathrm{n}(\%)$ \\
\hline $\begin{array}{l}\text { Diabetes duration (years): } \\
\quad \leq 5\end{array}$ & $145(51.8)$ \\
$>5$ & $135(48.2)$ \\
HbA1c (\%): & \\
$\quad \leq 6.5$ & $61(21.8)$ \\
$>6.5$ & $219(78.2)$ \\
Diabetes treatment: & \\
$\quad$ On insulin & $78(27.9)$ \\
$\quad$ On oral hypoglycemic drugs & $261(93.2)$ \\
Increased Waist circumference & $245(87.5)$ \\
Elevated blood pressure & $244(87.1)$ \\
Increased triglycerides level & $182(65)$ \\
Low HDL & $129(46.1)$ \\
Metabolic syndrome (MetS) & $233(83.2)$ \\
\hline
\end{tabular}

had MetS compared to those who did not have MetS ( $44.6 \%$ vs. $14.9 \%$ ). The prevalence of periodontal disease in patients with diabetes was significantly increased as the number of metabolic components increased $(P<0.005)$. Diabetes mellitus was associated with significantly higher prevalence of periodontal disease when accompanied with

Table 3 Extent and severity of periodontal disease according to metabolic syndrome (MetS) among 280 patients with type 2 diabetes

\begin{tabular}{|c|c|c|c|}
\hline \multirow[t]{3}{*}{ Variable } & \multicolumn{2}{|c|}{ Metabolic syndrome } & \multirow[t]{3}{*}{$P$-value* } \\
\hline & No $(n=47)$ & Yes $(n=233)$ & \\
\hline & Mean (SD) & Mean (SD) & \\
\hline $\begin{array}{l}\text { Average Probing Pocket } \\
\text { Depth (PPD) }\end{array}$ & $1.29(0.32)$ & $1.77(0.42)$ & $<0.005$ \\
\hline $\begin{array}{l}\text { Average Clinical Attachment } \\
\text { Level (CAL) }\end{array}$ & $1.52(1.34)$ & $2.86(1.59)$ & 0.001 \\
\hline
\end{tabular}

Average percent of teeth with deepest:

\begin{tabular}{lccc}
$P P D \geq 3$ & $1.00(2.83)$ & $11.08(21.89)$ & 0.038 \\
$P P D \geq 4$ & $0.33(1.36)$ & $7.03(20.77)$ & 0.159 \\
$P P D \geq 5$ & $0.0(0.0)$ & $5.24(20.43)$ & 0.297 \\
$P P D \geq 6$ & $0.0(0.0)$ & $4.40(20.30)$ & 0.392 \\
Average percent of teeth & & & \\
with deepest: & & & \\
$C A L \geq 3$ & $13.25(23.24)$ & $54.54(28.13)$ & $<0.005$ \\
$C A L \geq 4$ & $10.44(17.79)$ & $40.13(30.05)$ & $<0.005$ \\
$C A L \geq 5$ & $3.02(6.93)$ & $24.03(24.75)$ & $<0.005$ \\
$C A L \geq 6$ & $1.89(5.09)$ & $14.99(22.76)$ & 0.160 \\
\hline
\end{tabular}

*Adjusted for average PI, age, family income, residency area, smoking, teeth brushing, and number of missing teeth 
Table 4 Extent and severity of periodontal disease according to the number of metabolic syndrome (MetS) components among 280 patients with type 2 diabetes

\begin{tabular}{|c|c|c|c|c|c|}
\hline & \multicolumn{4}{|c|}{ The number of MetS components additional to diabetes mellitus } & \multirow[b]{2}{*}{$P$-value } \\
\hline & $\begin{array}{l}\text { One component } \\
n=31 \\
\text { Mean (SD) }\end{array}$ & $\begin{array}{l}\text { Two components } \\
n=52 \\
\text { Mean (SD) }\end{array}$ & $\begin{array}{l}\text { Three components } \\
n=115 \\
\text { Mean (SD) }\end{array}$ & $\begin{array}{l}\text { Four components } \\
n=82 \\
\text { Mean (SD) }\end{array}$ & \\
\hline Average Pocket Probing Depth (PPD) & $1.25(0.33)$ & $1.71(0.33)$ & $1.7(0.43)$ & $1.85(0.46)$ & $<0.005$ \\
\hline Average Clinical Attachment Level (CAL) & $1.11(1.22)$ & $2.33(1.3)$ & $2.85(1.6)$ & $3.1(1.65)$ & $<0.005$ \\
\hline \multicolumn{6}{|l|}{ Average percent of teeth with deepest: } \\
\hline$P P D \geq 3$ & $0.91(2.61)$ & $6.58(10.67)$ & $10.40(23.01)$ & $12.95(23.64)$ & 0.459 \\
\hline$P P D \geq 4$ & $0.38(1.53)$ & $1.82(5.17)$ & $7.21(22.43)$ & $8.76(22.36)$ & 0.345 \\
\hline$P P D \geq 5$ & $0.0(0.0)$ & $0.74(18.77)$ & $6.03(22.31)$ & $5.98(21.77)$ & 0.437 \\
\hline$P P D \geq 6$ & $0.0(0.0)$ & $0.07(0.5)$ & $5.32(22.32)$ & $5.00(21.66)$ & 0.433 \\
\hline \multicolumn{6}{|l|}{ Average percent of teeth with deepest: } \\
\hline$C A L \geq 3$ & $9.82(15.73)$ & $39.54(28.22)$ & $52.94(29.46)$ & $59.5(28.45)$ & $<0.005$ \\
\hline$C A L \geq 4$ & $6.95(13.07)$ & $27.27(27.04)$ & $39.01(28.72)$ & $45.34(32.2)$ & $<0.005$ \\
\hline$C A L \geq 5$ & $2.77(7.54)$ & $16.32(20.83)$ & $21.66(24.11)$ & $28.22(26.23)$ & 0.005 \\
\hline$C A L \geq 6$ & $1.04(3.34)$ & $6.99(9.93)$ & $13.08(20.61)$ & $20.48(27.99)$ & 0.004 \\
\hline
\end{tabular}

*Adjusted for average $\mathrm{Pl}$, age, family income, residency area, smoking, teeth brushing, and number of missing teeth

Table 5 Prevalence of periodontal disease among 280 patients with diabetes mellitus according to metabolic syndrome (MetS) and its components

\begin{tabular}{|c|c|c|c|}
\hline & \multicolumn{2}{|c|}{ Periodontitis } & \multirow[t]{2}{*}{$p$-value } \\
\hline & Non (\%) & Yesn (\%) & \\
\hline Metabolic syndrome (MetS) & & & $<0.005$ \\
\hline No & $40(85.1)$ & $7(14.9)$ & \\
\hline Yes & $129(55.4)$ & $104(44.6)$ & \\
\hline \multicolumn{4}{|l|}{$\begin{array}{l}\text { Number of metabolic } \\
\text { components additional to } \\
\text { diabetes mellitus }\end{array}$} \\
\hline 1 component & $29(93.5)$ & $2(6.5)$ & $<0.005$ \\
\hline 2 components & $32(61.5)$ & $20(38.5)$ & $<0.005$ \\
\hline 3 components & $72(62.6)$ & $43(37.4)$ & $<0.005$ \\
\hline 4 components & $36(43.9)$ & $46(56.1)$ & $<0.005$ \\
\hline Waist circumference & & & 0.011 \\
\hline Normal & $28(80)$ & $7(20)$ & \\
\hline Increased & $141(57.6)$ & $104(42.4)$ & \\
\hline Blood pressure & & & 0.119 \\
\hline Normal & $26(72.2)$ & $10(27.8)$ & \\
\hline Elevated blood pressure & $143(58.6)$ & $101(41.4)$ & \\
\hline Triglycerides & & & 0.005 \\
\hline Normal & $70(71.4)$ & $28(28.6)$ & \\
\hline Increased & $99(54.4)$ & $83(45.6)$ & \\
\hline $\mathrm{HDL}$ & & & 0.001 \\
\hline Normal & $105(69.5)$ & $46(30.5)$ & \\
\hline Low & $64(49.6)$ & $65(50.4)$ & \\
\hline
\end{tabular}

increased waist circumference $(P=0.011)$, increased triglycerides $(P=0.005)$, and decreased HDL $(P=0.001)$, but not when accompanied with hypertension $(P=0.119)$.

Model I in Table 6 shows that patients with MetS were almost 3 times $(\mathrm{OR}=3.28,95 \% \mathrm{CI}$ : 1.3-8.3) more likely to have periodontal disease compared to patients without MetS. In model II, patients with diabetes were about 6 times $(\mathrm{OR}=5.73,95 \% \mathrm{CI}: 1.15-28.59)$ more likely to have periodontal disease if they had two more components of MetS compared to those who had one additional component only. Patients who had all the other components of metabolic syndrome had much higher odds of having periodontal disease (OR $=10.77$, $95 \% \mathrm{CI}$ : 2.23-51.95) compared to those who had one additional component only. In model III, of the individual components of MetS, only HDL level was significantly associated with increased odds of having periodontal disease $(\mathrm{OR}=1.99$, 95 \% CI: 1.15-3.46).

\section{Discussion}

This study showed a positive association between periodontitis and MetS. Periodontitis was more common and severe in diabetic patients with MetS in Jordan compared to patients with no MetS. As the number of metabolic components additional to diabetes increased the severity and extent of periodontal disease increased.

Our study is the first in the Middle East that explores the association between MetS and periodontal disease among patients with diabetes. Other studies compared periodontal disease between patients with MetS and patients without MetS only without investigating the effect of individual components of MetS. 
Table 6 Multivariate analysis of association between metabolic syndrome (MetS) and its components with periodontal disease in separate models among 280 patients with diabetes mellitus

\begin{tabular}{ll}
\hline Odds ratio & -value ${ }^{*}$ \\
& $(95 \%$ confidence \\
& interval) of having \\
& periodontitis
\end{tabular}

Model I

Metabolic syndrome (MetS)

No

Yes

Model II: Number of MetS

additional to diabetes

1 component

2 components

3 components

4 components

Model III: Individual components

of MetS

Waist circumference

Normal

Increased

1

$1.74(0.63,4.79)$

0.286

Blood pressure

Normal

Elevated

1

$1.12(0.43,2.90)$

Triglycerides

Normal

Increased

$\mathrm{HDL}$

$\begin{array}{ll}\text { Normal } & 1 \\ \text { Low } & 1.99(1.15,3.46)\end{array}$

*In the three models, the associations between periodontal disease and metabolic syndrome, individual components, and their combinations were adjusted for average $\mathrm{Pl}$, age, family income, residency area, smoking, teeth brushing, and number of missing teeth

The findings of this study are consistent with the study conducted by Khader et al. (2008) [19] in Jordan and are in support of other studies' findings [20,21]. Shimazaki et al. (2007) [28] reported that MetS is associated with increased risk of periodontal disease among Japanese women. On the other hand, Morita et al. (2010) [16] concluded that presence of periodontal pockets was associated with a positive conversion of MetS components, suggesting that preventing periodontal disease may prevent MetS. These studies may propose a two way relationship. However, longitudinal and interventional studies should be performed to investigate such a relationship.

In this study when each component additional to diabetes was analyzed separately, increased waist circumference (WC) and low HDL level were associated with significantly higher extent and severity of periodontal disease. Increased triglycerides (TG) level was associated with significant increase in the extent but not severity of periodontal disease, while hypertension was not significantly associated with either extent or severity of periodontal disease. This was comparable with the results reported by Shimazaki et al. (2007) [28], as increased WC, low HDL and fasting blood sugar had significant relationships with periodontal disease.

In contrast, Kushiyama et al. (2009) [20] reported that of the five MetS components, only high blood pressure and low HDL were each significantly associated with deep probing depths.

When the extent and severity of periodontal disease were analyzed according to the number of MetS components in multivariate analysis, the number of components additional to diabetes increased was associated with increased extent and severity of periodontal disease. This finding was consistent with results of other studies $[15,19,20,28]$. It is important to mention that these studies were designed to compare periodontal disease between patients with MetS and patients without MetS, but not in patients who had diabetes and MetS. In this study, the effect of diabetes on periodontal disease was the principal factor to which the effect of other components was added, while the other studies did not take into consideration the well established relationship between diabetes and periodontal disease.

In our study, obesity was significantly associated with higher extent and severity of periodontal disease. This finding was consistent with the findings of another study in Jordan by Khader et al. (2009) [29]. Low HDL level was strongly associated with increased extent and severity of periodontal disease, while elevated TG levels were associated with significant increase in average CAL (severity) and percent of teeth with deepest $\mathrm{CAL} \geq 3, \geq 4 \mathrm{~mm}$ (extent). These findings are in agreement with the study conducted by Fentoğlu et al. (2009) [30]. However, Saxlin et al. (2008) [31] found no association between level of serum lipids and periodontal disease in normal-weight subjects, while obese subjects with high TG levels, and/or low HDL levels could be at high risk of periodontal disease.

Diabetic patients who had MetS had significantly higher prevalence of periodontal disease than those without MetS. This finding confirmed the results of Li et al. (2009) [15] and Kushiyama et al. (2009) [20]. In this study the prevalence of periodontitis in patients with diabetes was significantly increased as the number of MetS components increased. This was similar to other studies; Kushyiama et al. (2009) [20] concluded that subjects with three, four or five components of MetS exhibited a significantly higher prevalence of periodontal disease and $\mathrm{Li}$ et al. (2009) [15] found that prevalence of periodontal disease was less in subjects bearing fewer than two of metabolic components. Also, Hasegawa et al. (2004) [32] 
observed that Japanese urban women who had three or more components had a higher prevalence of periodontal disease than those who had less than two components.

In this study only low HDL level was significantly associated with increased odds of having periodontal disease in the multivariate analysis. Alike, Shimazaki et al. (2007) [28] reported that of the five components of MetS, low HDL level had the highest odds ratio and was statistically significant for a greater PPD and CAL. Similarly, Nibali et al. (2007) [33] reported that periodontitis exhibited a significant association with low HDL, high LDL, and elevated fasting blood sugar.

In conclusion, patients with MetS displayed more severe and extensive periodontitis. Having other MetS components additional to diabetes increased the odds of having periodontitis. Given the study design we used, our findings reflect the cumulative and additive effects of metabolic abnormalities on the risk of periodontal disease. Longitudinal and interventional studies are needed to confirm the study findings.

\section{Competing interests}

The authors declare that they have no competing interests.

\section{Authors' contributions}

RA main researcher, supervise data collection, and dental examination writing manuscript. YK data analyses, editted the manuscript. ZH data collection, examination, thesis writing. FA writing results, manuscript editting. All authors read and approved the final manuscript.

\section{Source of funding statement}

This study was partially supported by the University of Science and Technology Research Fund.

Received: 28 January 2015 Accepted: 15 July 2015

Published online: 16 August 2015

\section{References}

1. Eckel RH, Grundy SM, Zimmet PZ. The metabolic syndrome. Lancet. 2005;365(9468):1415-28.

2. Onat A. Metabolic syndrome: nature, therapeutic solutions and options. Expert Opin Pharmacother. 2011;12(12):1887-900.

3. Beltrán Sánchez H, Harhay MO, Harhay MM, McElligott S. Prevalence and trends of metabolic syndrome in the adult U.S. population, 1999-2010. J Am Coll Cardiol. 2013;62(8):697-703.

4. Riediger ND, Clara I. Prevalence of metabolic syndrome in the Canadian adult population. CMAJ. 2011;183(15):E1127-34.

5. Abdul-Rahim HF, Husseini A, Bjertness E, Giacaman R, Gordon NH, Jervell J. The metabolic syndrome in the West Bank population: An urban-rural comparison. Diabetes Care. 2001;24(2):275-9.

6. Al-Lawati JA, Mohammed AJ, Al-Hinai HQ, Jousilahti P. Prevalence of the metabolic syndrome among Omani adults. Diabetes Care. 2003;26(6):1781-5.

7. Jaber LA, Brown MB, Hammad A, Zhu Q, Herman WH. The prevalence of the metabolic syndrome among Arab Americans. Diabetes Care. 2004;27(1):234-8.

8. Onat A Ceyhan K, Basar Ö, Erer B, Toprak S, Sansoy V. Metabolic syndrome: major impact on coronary risk in a population with low cholesterol levels - a prospective and cross-sectional evaluation. Atherosclerosis. 2002;165:285-9.

9. Zabetian A, Hadaegh F, Azizi F. Prevalence of metabolic syndrome in Iranian adult population, concordance between the IDF with the ATPIII and the WHO definitions. Diabetes Res Clin Pract. 2007;77:251-7.

10. Khader Y, Bateiha A, El-Khateeb M, Al-Shaikh A, Ajlouni K. High prevalence of the metabolic syndrome among Northern Jordanians. J Diabetes Complicat. 2007;21(4):214-9.
11. Hu G, Qiao Q, Tuomilehto J, Balkau B, Borch-Johnsen K, Pyorala K, et al Prevalence of the metabolic syndrome and its relation to all-cause and cardiovascular mortality in nondiabetic European men and women. Arch Intern Med. 2004;164:1066-76.

12. Page RC, Kornman KS. The pathogenesis of human periodontitis. Periodontol. 2000;14:9-11.

13. Loesche WJ, Grossman NS. Periodontal disease as a specific, albeit chronic, infection: diagnosis and treatment. Clin Microbial Rev. 2001;14(4):727-52.

14. Eke PI, Dye BA, Wei L, Thornton-Evans GO. Prevalence of periodontitis in adults in the United States: 2009 and 2010. Dent Res J. 2012;91(10):914-20.

15. Li P, He L, Sha Y, Luan Q. Relationship of metabolic syndrome to chronic periodontitis. J Periodontol. 2009;80(4):541-9.

16. Morita T, Yamazaki Y, Mita A, Takada K, Seto M, Nishinoue N, et al. A cohort study on the association between periodontal disease and the development of metabolic syndrome. J Periodontol. 2010;81(4):512-9.

17. Abreu LMG, Lopes FF, Pereira AFV, Pereira ALA, Alves CMC. The interface between metabolic syndrome and periodontal disease. RSBO. 2012;9(4):434-41.

18. Gurav AN. The association of periodontitis and metabolic syndrome. Dent Res J (Isfahan). 2014;11(1):1-10.

19. Khader Y, Khassawneh B, Obeidat B, Hammad M, El-Salem K, Bawadi H, et al. Periodontal status of patients with metabolic syndrome compared to those without metabolic syndrome. J Periodontol. 2008;79(11):2048-53.

20. Kushiyama M, Shimazaki Y, Yamashita Y. Relationship between metabolic syndrome and periodontal disease in Japanese adults. J Periodontol. 2009;80(10):1610-5.

21. Benquiqui C, Bongrad V, Ruidavets JB, Chamontin B, Sixous M, F Errieres J, et al. Metabolic syndrome, insulin resistance, and periodontitis: a crosssectional study in a middle-aged French population. J Clin Periodontol. 2010;37(7):601-8.

22. Nibali L, Tatarakis N, Needleman I, Tu YK, D’Aiuto F, Rizzo M, et al. Association between metabolic syndrome and periodontitis: a systematic review and meta-analysis. J Clin Endocrinol Metab. 2013;98(3):913-20.

23. Janket SJ, Wightman A, Baird AE, Van Dyke TE, Jones JA. Does periodontal treatment improve glycemic control in diabetic patients? A meta-analysis of intervention studies. JDent Res. 2005;84(12):1154-9.

24. lacopino AM, Cutler CW. Path physiological relationships between periodontitis and systemic disease: recent concepts involving serum lipids. J Periodontol. 2000;71(8):1375-84.

25. Alberti KG, Zimmet P, Shaw J. IDF Epidemiology task force consensus group. The metabolic syndrome-a new worldwide definition. Lancet. 2005;366:1059-62.

26. Silness J, Loe H. Periodontal disease in pregnancy II. Correlation between oral hygiene and periodontal condition. Acta Odontol Scand. 1964;22:121-35.

27. Brown LJ, Brunelle JA, Kingman A. Periodontal status in the United States, 1988-1991: Prevalence, extent, and demographic variation. J Dent Res. 1996;75:672-83.

28. Shimazaki Y, Saito T, Yonemoto K, Kiyohara Y, lida M, Yamashita Y. Relationship of metabolic syndrome to periodontal disease in Japanese women: the Hisayama Study. J Dent Res. 2007:86(3):271-5.

29. Khader YS, Bawadi HA, Haroun TF, Alomari M, Tayyem RF. The Association between periodontal disease and obesity among adults in Jordan. J Clin Periodontol. 2009;36(1):18-24

30. Fentoğlu $\mathrm{O}, \mathrm{Oz}$ G, Taşdelen P, Uskun E, Aykaç Y, Bozkurt FY. Periodontal status in subjects with hyperlipidemia. J Periodontol. 2009;80(2):267-73.

31. Saxlin T, Suominen-Taipale L, Kattainen A, Marniemi J, Knuuttila M, Ylostalo P. Association between serum lipid levels and periodontal infection. J Clin Periodonto. 2008;35(12):1040-7.

32. Hasegawa T, Watase H. Multiple risk factors of periodontal disease: A study of 9260 Japanese nonsmokers. Geriatr Gerontol Int. 2004;4(1):37-43.

33. Nibali L, D'Aiuto F, Griffiths G, Patel K, Suvan J, Tonetti MS. Severe periodontitis is associated with systemic inflammation and a dysmetabolic status: a case-control study. J Clin Periodontol. 2007;34(11):931-7. 